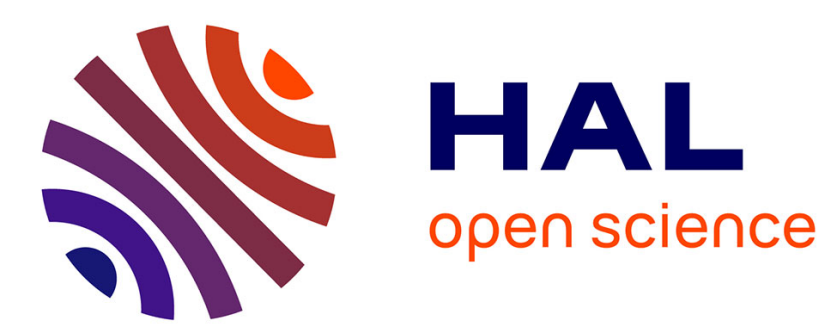

\title{
Dynamic cratering of graphite: Experimental results and simulations
}

\author{
Gabriel Seisson, D. Hébert, I. Bertron, Jean-Michel Chevalier, Ludovic Hallo, \\ E. Lescoute, I. Videau, Patrick Combis, F. Guillet, M. Boustie, et al.
}

\section{- To cite this version:}

Gabriel Seisson, D. Hébert, I. Bertron, Jean-Michel Chevalier, Ludovic Hallo, et al.. Dynamic cratering of graphite: Experimental results and simulations. International Journal of Impact Engineering, 2013, 63, pp.18-28. 10.1016/j.ijimpeng.2013.08.001 . hal-00980631

\section{HAL Id: hal-00980631 https://hal.science/hal-00980631}

Submitted on 16 May 2014

HAL is a multi-disciplinary open access archive for the deposit and dissemination of scientific research documents, whether they are published or not. The documents may come from teaching and research institutions in France or abroad, or from public or private research centers.
L'archive ouverte pluridisciplinaire HAL, est destinée au dépôt et à la diffusion de documents scientifiques de niveau recherche, publiés ou non, émanant des établissements d'enseignement et de recherche français ou étrangers, des laboratoires publics ou privés. 


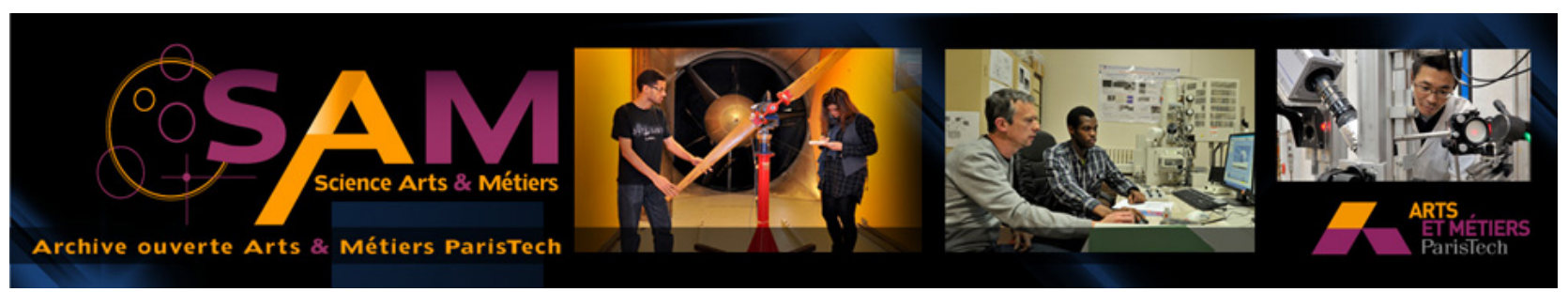

\section{Science Arts \& Métiers (SAM)}

is an open access repository that collects the work of Arts et Métiers ParisTech researchers and makes it freely available over the web where possible.

This is an author-deposited version published in: http://sam.ensam.eu

Handle ID: .http://hdl.handle.net/10985/7986

\section{To cite this version :}

G SEISSON, D HEBERT, I BERTRON, J.M CHEVALIER, L HALLO, E LESCOUTE, L VIDEAU, P COMBIS, F GUILLET, Laurent BERTHE - Dynamic cratering of graphite: Experimental results and simulations - International Journal of Impact Engineering - Vol. 63, p.18-28 - 2013 


\title{
Dynamic cratering of graphite: Experimental results and simulations
}

\author{
G. Seisson ${ }^{\mathrm{a}, *}$, D. Hébert ${ }^{\mathrm{a}}$, I. Bertron ${ }^{\mathrm{a}}$, J.-M. Chevalier ${ }^{\mathrm{a}}$, L. Hallo ${ }^{\text {a }}$, E. Lescoute ${ }^{\mathrm{b}}$, L. Videau ${ }^{\mathrm{b}}$, \\ P. Combis ${ }^{\text {b }}$, F. Guillet ${ }^{\text {c }}$, M. Boustie ${ }^{\mathrm{d}}$, L. Berthe ${ }^{\mathrm{e}}$ \\ ${ }^{a}$ CEA CESTA, 15 avenue des Sablières CS60001, 33116 Le Barp Cedex, France \\ ${ }^{\mathrm{b}}$ CEA DIF, 91297 Arpajon, France \\ ${ }^{\mathrm{C}}$ CEA LR, BP 16, 37260 Monts, France \\ 'Institut P' UPR3346 CNRS-ENSMA-Université de Poitiers, 1 avenue Clément Ader, 86961 Futuroscope Cedex, France \\ e Laboratoire PIMM UPR8006 CNRS-Arts et Métiers ParisTech, 151 boulevard de l'Hôpital, 75013 Paris, France
}

Keywords:

Hypervelocity impact

Porous graphite

Hydrocode simulation

Laser-induced shock

Energy partitioning

\begin{abstract}
A B S T R A C T
The cratering process in brittle materials under hypervelocity impact (HVI) is of major relevance for debris shielding in spacecraft or high-power laser applications. Amongst other materials, carbon is of particular interest since it is widely used as elementary component in composite materials. In this paper we study a porous polycrystalline graphite under HVI and laser impact, both leading to strong debris ejection and cratering. First, we report new experimental data for normal impacts at 4100 and $4200 \mathrm{~m} \mathrm{~s}$

${ }^{-1}$ of a $500-\mu \mathrm{m}$-diameter steel sphere on a thick sample of graphite. In a second step, dynamic loadings have been performed with a high-power nanosecond laser facility. High-resolution X-ray tomographies and observations with a scanning electron microscope have been performed in order to visualize the crater shape and the subsurface cracks. These two post-mortem diagnostics also provide evidence that, in the case of HVI tests, the fragmented steel sphere was buried into the graphite target below the crater surface. The current study aims to propose an interpretation of the results, including projectile trapping. In spite of their efficiency to capture overall trends in crater size and shape, semi-empirical scaling laws do not usually predict these phenomena. Hence, to offer better insight into the processes leading to this observation, the need for a computational damage model is argued. After discussing energy partitioning in order to identify the dominant physical mechanisms occurring in our experiments, we propose a simple damage model for porous and brittle materials. Compaction and fracture phenomena are included in the model. A failure criterion relying on Weibull theory is used to relate material tensile strength to deformation rate and damage. These constitutive relations have been implemented in an Eulerian hydrocode in order to compute numerical simulations and confront them with experiments. In this paper, we propose a simple fitting procedure of the unknown Weibull parameters based on HVI results. Good agreement is found with experimental observations of crater shapes and dimensions, as well as debris velocity. The projectile inclusion below the crater is also reproduced by the model and a mechanism is proposed for the trapping process. At least two sets of Weibull parameters can be used to match the results. Finally, we show that laser experiment simulations may discriminate in favor of one set of parameters.
\end{abstract}

\section{Introduction}

Debris shielding against hypervelocity impact (HVI) is a major concern for many applications such as spacecraft technology and high-power laser facilities. Indeed, meteoroids can impact satellites at several kilometers per second, possibly damaging or destroying some vital equipment $[1,2]$. Moreover, ejecta created by HVI may

\footnotetext{
* Corresponding author.

E-mail addresses: gabriel.seisson@cea.fr, gabriel.seisson@gmail.com (G. Seisson).
}

remain in orbit and collide with other man-made space structures [3]. Similarly, the various instruments of the Laser MégaJoule (LMJ) experiment chamber can be hit by a variety of shrapnel and debris originating from the target assembly [4,5].

The range of materials exposed to HVI continuously increases. Metals have been widely studied, both experimentally [6] and through the use of numerical hydrocodes [7]. Some brittle materials have also been included in HVI studies, such as geophysical materials [8], and silica glass that covers solar arrays or can be used as transparent windows [9]. Experiments and hydrodynamic simulations have emphasized their difference with ductile metals [10]. 
Due to their low density and high mechanical properties, composite materials are now more and more being used in the aerospace industry. For instance, the behavior of composites with carbon components has been examined under HVI $[11,12]$. Experimental results have been recently published which give crater dimensions in porous graphite for a variety of projectile materials and velocities [13]. However, in order to improve the predictive capabilities of hydrodynamic simulations for such materials, it appears that modeling porous graphite is needed.

In this paper we focus on experiments leading to crater formation in EDM3 [14], a commercial grade of polycrystalline graphite approximately $20 \%$ porous and macroscopically isotropic. In the following section, we describe dynamic experiments on thick targets and present new results: impacts of a $0.5-\mathrm{mm}$-diameter steel sphere around $4 \mathrm{~km} \mathrm{~s}^{-1}$ obtained with MICA, a two-stage light-gas gun. Post-mortem tomographies and Scanning Electron Microscope (SEM) observations on the recovered samples indicate that the fragmented sphere is buried below the target surface. It implies that the apparent crater dimensions are not sufficient to characterize the damaged zone in the graphite sample. One of the major goals of this paper is to analyze this result. A complementary experiment has been performed through direct irradiation with LULI 2000 [15], a nanosecond (ns) high-power laser, generating significantly different pressures and strain rates in the sample. The resulting crater morphology and profile are provided and compared to HVI tests. In the Third Section, a discussion on HVI experiments consists in order of magnitude calculations. Section 4 is devoted to numerical analysis. A model for isotropic brittle materials is constructed which accounts for porosity and has been implemented into Hésione, an Eulerian hydrocode. Finally, we perform and discuss simulations and compare them with experimental observations.

\section{Experimental}

\subsection{HVI experiments}

\subsubsection{Experimental set-up}

We study the case of a $0.5-\mathrm{mm}$-diameter stainless-steel sphere (its precise grade is unknown) which orthogonally impacts a 30 mm-diameter, 15-mm-thickness graphite target. The samples were made of EDM3, which is a porous isotropic and homogeneous graphite from the POCO Company [14]. Its mechanical characteristics are summarized in Table 1 and Fig. 9.

The projectile is launched by MICA, a two-stage light-gas gun located at CEA CESTA and represented in Fig. 1. Combustion of the first stage propellant powder compresses the second-stage gas with a moving piston. When a critical pressure is exceeded the diaphragm breaks off and the polycarbonate sabot containing the steel sphere is launched from the second stage tube to the

Table 1

Mechanical characteristics of EDM3.

\begin{tabular}{lll}
\hline Density $\left(\mathrm{kg} \mathrm{m}^{-3}\right)$ & Porous $\left(\rho_{0}\right)$ & 1754 \\
& Compact $\left(\rho_{s 0}\right)$ & 2265 \\
Young modulus $E(\mathrm{GPa})$ & Tension & 11 \\
& Compression & 12 \\
Failure stress $\sigma_{r}(\mathrm{MPa})$ & Tension & 70 \\
& Compression & 140 \\
Failure stain $\varepsilon_{r}(\%)$ & Tension & 1 \\
& Compression & 8 \\
Bulk modulus $K(\mathrm{GPa})$ & & 9.6 \\
Poisson ratio $\nu$ & & 0.3 \\
Porosity & & $\sim 20 \%$ \\
Characteristic grain size $(\mu \mathrm{m})$ & & $\leq 5$ \\
\hline
\end{tabular}

experiment chamber. The chamber is filled with a low pressure argon atmosphere which enables the pre-cut sabot to split into two parts while the steel projectile goes on toward the target. A velocity sensor records the sabot velocity at the launching tube exit. In reported experiments, impact velocities are slightly above $4 \mathrm{~km} \mathrm{~s}^{-1}$. Transverse pictures of sample and ejecta are taken by a high-speed camera.

\subsubsection{Debris velocity measurements}

An impact was recorded at 43,000 images per second with a high-speed camera. The video, from which Fig. 2 was extracted, allows to follow the position of ejected fragments, hence their velocity. It ranges from 10 to $200 \mathrm{~m} \mathrm{~s}^{-1}$.

\subsubsection{Crater morphology and discussion}

The crater appearance and dimensions were given by tomography and contact profilometry. Fig. 3 shows tomographic, i.e. nondestructive, slices into the graphite target. The crater is like a 45degree cone and one can see a spalling zone around the crater on the free surface. We can also note fragmented zones near the crater walls. Characteristic dimensions of craters are summarized in Table 2.

However, the projectile being buried into the sample suggests that the apparent crater may not be sufficient to characterize all the damage process. Because the projectile dazzles around itself on tomographies, this aspect is more evident when the latter are correctly thresholded, analyzed and transformed into volumetric objects. Fig. 4 presents such volumetric reconstructions of shots \#38 and \#41. It clearly points out that graphite closed up right behind the steel projectile.

The volume of the projectile is significantly reduced by thresholding but its validity is confirmed by Fig. 5. It was made by SEM after epoxy resin coating, cutting across the crater center and polishing. The white veins inside graphite stem from superficial melting of the steel sphere. Moreover, damaged area is visible and restricted to a zone close to the crater surface. There is no apparent long radial cracks.

Projectile trapping has already been reported by Tanabe et al. [16] for experiments carried at lower velocities (600-1500 $\mathrm{m} \mathrm{s}^{-1}$ ) and with ferrite impactor. The mechanism of this particular behavior remains unclear and its sensitivity to projectile and sample physical properties should be addressed. Tanabe noticed that the projectile capture was not observed for specimen with the highest bending strength, Shore hardness and elastic modulus. In the following of this paper, hydrodynamic simulations with a physically based model of EDM3 are used as an attempt to clarify this point.

In view of the fact that strain rate dependency on tensile failure stress is a key feature of dynamic failure [10], we performed a cratering experiment with a nanosecond laser, higher strain rates being expected. This choice is precisely explained in the next section, where the analogy between those two kinds of dynamic loading is discussed, along with new experimental results.

\subsection{Laser-induced shock}

\subsubsection{Orders of magnitude and experimental set-up}

Pirri [17] evidenced the similarity between HVI and laserinduced shocks. Indeed, the interaction of nanosecond laser and solid targets at intensities above several $\mathrm{GW} \mathrm{cm}^{-2}$ generates a plasma whose expansion leads to shock wave propagation in the target. This shock wave is followed by a release wave at the end of the laser pulse. Similarly, the shock wave resulting from the projectile impact at velocities of several $\mathrm{km} \mathrm{s}^{-1}$ is followed by a release wave. The latter is due to the propagation of a second shock in the 


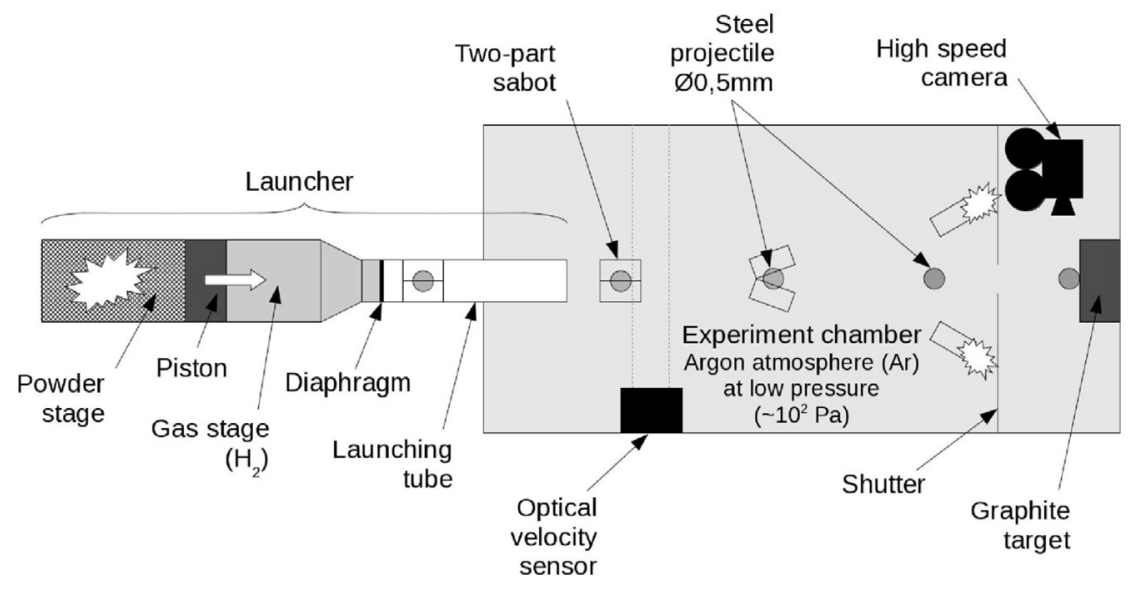

Fig. 1. The MICA two-stage light-gas gun from CEA.

projectile which decelerates it and reflects on its rear side. Considering that the major parameters governing the target mechanical response, including cratering, are the shock pressure $P_{S}$ and the stress duration $\tau$ between shock and release, Pirri [17] suggests a way to derive equivalence relations between laser and projectile parameters.

If we consider a steel projectile and a $20 \%$ porous graphite target, shock pressure $P_{s}$ is directly related to impact velocity $v_{p}$ and can be deduced from Ref. [18]. Thus, in HVI experiments described above, $P_{S} \sim 40 \mathrm{GPa}$, and stress duration $\tau$ is estimated from the projectile thickness (i.e. its diameter) $d_{p}=0.5 \mathrm{~mm}$ and its shock velocity $U_{s p}=6000 \mathrm{~m} \mathrm{~s}^{-1}: \tau \sim 2 d_{p} / U_{s p} \sim 2 \cdot 10^{-7} \mathrm{~s}$.

We used the LULI 2000 high-power laser facility (see Fig. 6) from École Polytechnique (Palaiseau, France). Its wave-length $\lambda$ is $1054 \mathrm{~nm}$ and the maximum intensity was $5 \mathrm{TW} \mathrm{cm}^{-2}$ with a $2-\mathrm{mm}-$ diameter spot. The pulse duration was $\sim 4$ ns. Energy deposition was directly performed on EDM3 sample in an evacuated vessel. In order to estimate the induced shock pressure $P_{S}$ (in GPa), we used the semi-empirical scaling law proposed in Ref. [19]:

$P_{S}=1180 \cdot\left(\frac{I_{b}}{10^{5}}\right)^{2 / 3} \cdot\left(\frac{A}{2 Z}\right)^{1 / 3} \cdot\left(\frac{\lambda}{1060}\right)^{-2 / 3}$

where $I_{b}$ is the beam intensity (in $\mathrm{GW} \mathrm{cm} \mathrm{cm}^{-2}$ ), $A$ and $Z$ are the target atomic mass and number respectively, and $\lambda$ is expressed in $\mathrm{nm}$. This yields $P_{S} \sim 160 \mathrm{GPa}$. However, this formula may lead to overestimation for the considered intensity. In this regime, the empirical Grün formula [20] is known to give better results for aluminum targets:

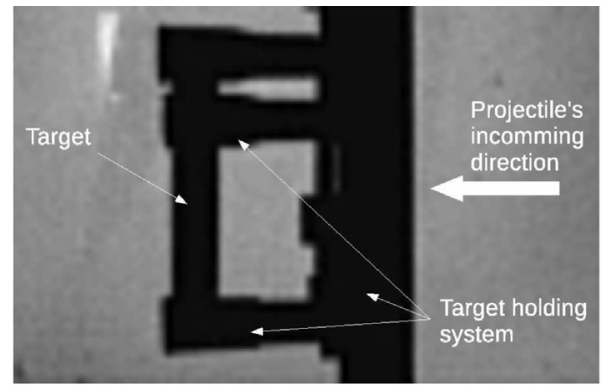

(a) Before impact.

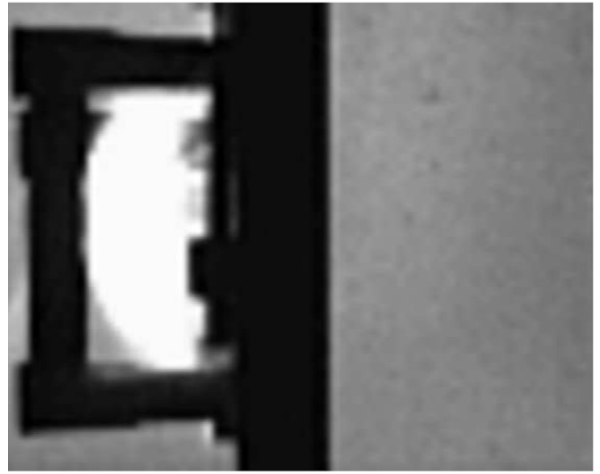

(b) $\leqslant 20 \mu$ s after impact.

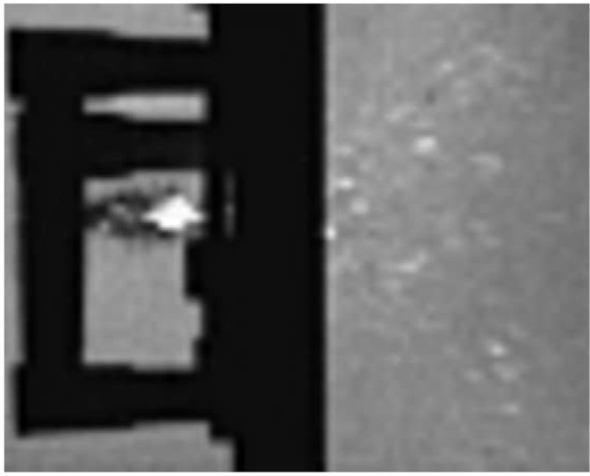

(c) About $150 \mu$ s after impact.

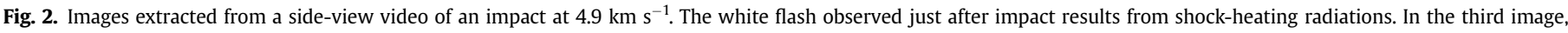
ejected particles from impacted face are visible. 


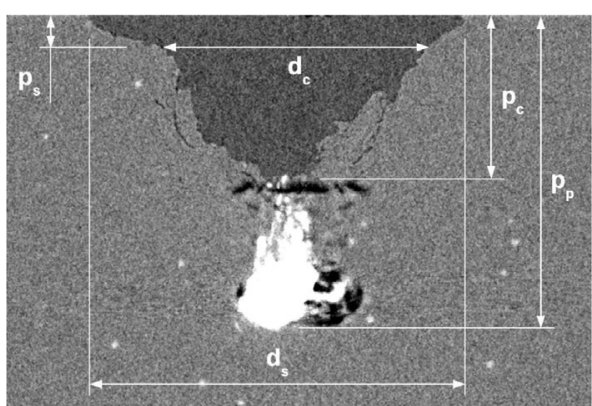

(a) Shot \#38.

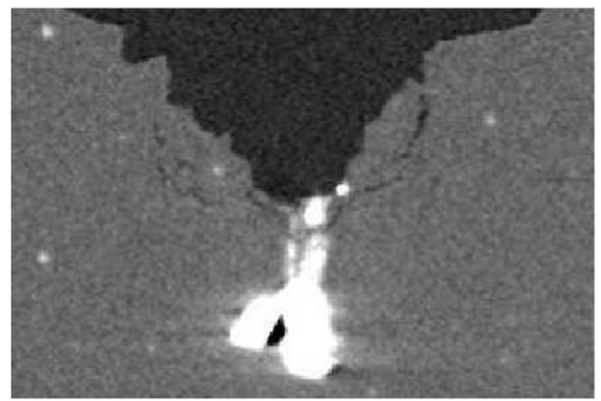

(b) Shot \#41.

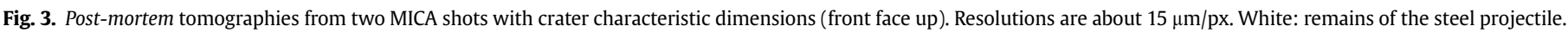
Gray: EDM3 sample. Black (or dark gray): empty spaces. The small white dots into graphite are metallic inclusions (vanadium and titanium) arising from production cycle.

$$
P_{s}=1440 \cdot\left(0.8 \cdot \frac{I_{b}}{10^{5}}\right)^{0.8}
$$

It yields $P_{S} \sim 110 \mathrm{GPa}$. In view of the weak dependence of Eq. (1) to the target material, we consider the latter formula to be valid for graphite and assume that the maximum pressure on the target surface to be close to $110 \mathrm{GPa}$. Hence, this laser configuration will produce higher pressure and smaller stress duration $(\tau \sim 4 \mathrm{~ns})$ than HVI experiments: significantly different strain rates are to be expected.

\subsubsection{Crater observations}

Post-mortem analysis of the apparent crater was done by interferometric profilometry, using the VEECO Contour GTK1 profilometer from CEA CESTA. It performs series of topographic profiles of the crater area which can be reconstructed in $3 \mathrm{D}$, as presented in Fig. 7a. A high-resolution tomographic slice which crosses the crater center is also shown in Fig. 7b. Along with previous authors [21], we note that the apparent crater shape is similar to those resulting from MICA shots, but it appears asymmetric. However, there is a long subsurface crack on the right side almost up to the surface. We will consider this large fragment ejected. In this way the crater shape becomes symmetric and its characteristics are described in Table 3.

\section{Discussion of the HVI experimental results}

In this section, we try to analyze the effects of an impact at $4 \mathrm{~km} \mathrm{~s}^{-1}$ of a $500-\mu \mathrm{m}$-diameter steel sphere such as crater volume, characteristic fragment size and ejected fragmented volume. A possibility is to build semi-empirical models predicting crater depth and/or diameter as functions of impact conditions and mechanical properties of the target.

Table 2

Craters characteristic dimensions from two MICA shots.

\begin{tabular}{|c|c|c|c|c|}
\hline Shot & & \#38 & & \#41 \\
\hline Projectile velocity $v_{p}\left(\mathrm{~m} \mathrm{~s}^{-1}\right)$ & 4200 & Normalized by & 4100 & Normalized by \\
\hline $\begin{array}{l}\text { Crater volume (with spall) } \\
\quad V_{\text {crat }}\left(\mathrm{mm}^{3}\right)\end{array}$ & 3.6 & $\begin{array}{l}\text { the projectile } \\
\text { diameter } d_{p}\end{array}$ & 3.2 & $\begin{array}{l}\text { the projectile } \\
\text { diameter } d_{p}\end{array}$ \\
\hline Projectile diameter $d_{p}(\mathrm{~mm})$ & 0.5 & & 0.5 & \\
\hline Projectile depth $p_{p}(\mathrm{~mm})$ & 2.7 & 5.4 & 2.7 & 5.4 \\
\hline Crater depth $p_{c}(\mathrm{~mm})$ & 1.45 & 2.9 & 1.2 & 2.4 \\
\hline Crater diameter $d_{c}(\mathrm{~mm})$ & 2.1 & 4.2 & 2.3 & 4.6 \\
\hline Spall depth $p_{s}(\mathrm{~mm})$ & 0.29 & 0.58 & 0.24 & 0.48 \\
\hline Spall diameter $d_{s}(\mathrm{~mm})$ & 3.5 & 7 & 3.4 & 6.8 \\
\hline
\end{tabular}

\subsection{Semi-empirical scaling laws}

Semi-empirical scaling laws have shown their efficiency to capture crater depth and diameter in case of ductile targets. Amongst the most popular, one can notice models from Cour-Palais [1], Davison et al. [2] and Tokheim et al. [22] which have generally the following form:

$P$ or $D \propto \rho_{p}^{\alpha} \cdot d_{p}^{\beta} \cdot v_{p}^{\gamma}$

where $P$ and $D$ are the crater depth and diameter, $\rho_{p}$ the projectile density, $d_{p}$ the projectile diameter and $v_{p}$ the impact velocity. $\alpha, \beta$ and $\gamma$ are fitting parameters. Herrmann and Jones [6] and Shanbing et al. [23] discussed these scaling laws, but their analysis mostly relied on data using metallic targets. Concerning impacts on graphite targets, a same kind of model was proposed by LatundeDada et al. [13]. Although sample densities are very close in both studies, their model for steel projectile impacts at velocities above $2.5 \mathrm{~km} \mathrm{~s}^{-1}$ does not match our results: overestimation can reach $40 \%, 60 \%$ and $35 \%$ respectively for depth $p_{c}$, diameter $d_{s}$ and aspect ratio $d_{s} / p_{c}$. This is not surprising if one remembers that mechanical properties such as fracture toughness $K_{I c}$ and hardness $H$ play a significant role in the cracking process of brittle materials. Following this idea, Evans et al. [24] and Wiederhorn and Lawn $[25,26]$ elaborated models using these static material properties. Their approach was extended to impact velocities up to $2000 \mathrm{~m} \mathrm{~s}^{-1}$ with a 4-mm-diameter ferrite sphere by Tanabe et al. [16,27], taking the Young modulus $E$ into account:

$V_{\text {crat }} \propto K_{I C}^{\alpha} \cdot v_{p}^{\beta} \cdot H^{\gamma} \cdot E^{\delta}$

where $V_{\text {crat }}$ is the crater volume and $\delta$ another fitting parameter. However this model does not include scaling with projectile size and density. Assuming a simple (linear) scaling between crater and projectile volumes, the direct use of parameters from Ref. [16] for shot \#38 leads to $V_{\text {crat }}=27 \mathrm{~mm}^{3}$ which is eight times the measured crater volume. Note that this assumption is equivalent to a scaling of the crater volume with kinetic energy of impact $[6,23]$.

Semi-empirical models such as Eqs. (3) and (4) can be quite efficient but require a large experimental database, which is not available for EDM3 graphite. Moreover, the projectile inclusion below the crater surface ( $c f .2 .1 .3$ ) suggests that the apparent crater size and shape are not the sole relevant parameters. In order to estimate densification zones or ejections, the following of this section establishes that energy balance (or energy partitioning) study may provide better insight into these processes $[28,29]$. 


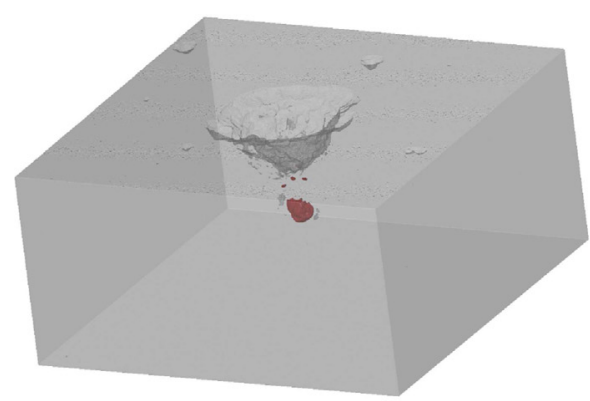

(a) Shot \#38.

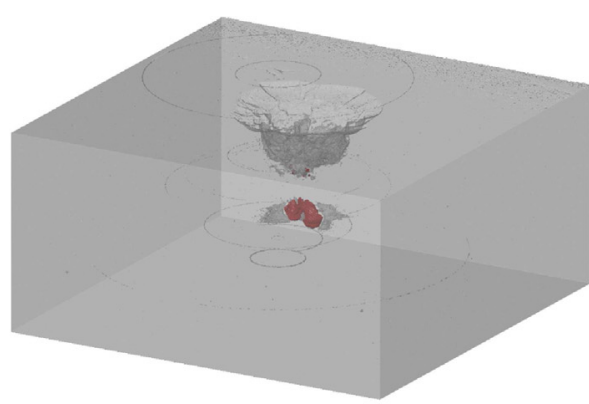

(b) Shot \#41.

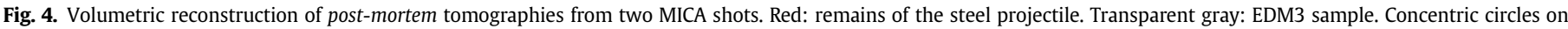
\#41 are tomography artifacts. (For interpretation of the references to color in this figure legend, the reader is referred to the web version of this article.)

\subsection{Energy balance method}

For a 0.5 -mm-diameter steel projectile with an impact velocity $v_{p}=4.2 \mathrm{~km} \mathrm{~s}^{-1}$, the input energy is the projectile kinetic energy $E_{p}^{k i n}=4.5 \mathrm{~J}$. According to experimental data, we will assume that the projectile does not rebound. Thus, the energy balance equation can be written as follows:

$E_{p}^{k i n}=E_{p}^{s r}+E_{p}^{p l a s}+E_{t}^{k i n}+E_{t}^{c o m p}+E_{f}^{k i n}+E^{\text {frag }}$

$E_{p}^{s r}$ and $E_{p}^{\text {plas }}$, which are respectively the energy dissipated in the shock-release path and the plastic strain energy, account for the thermal energy stored in the projectile. The energy transferred into the target is divided between kinetic energy $E_{t}^{\text {kin }}$, irreversible compression energy $E_{t}^{\text {comp }}$, kinetic energy of ejected fragments $E_{f}^{\text {kin }}$ and fragmentation energy (new free surface creation) $E^{\text {frag }}$. It has been shown that the thermal energy can be much greater in a porous material than in a dense one [30] due to larger volume change in the compaction process. Although it does not explicitly appear, we do not ignore it since it is included in $E_{t}^{\text {comp }}$. In further discussions, we estimate the contribution of each of them to energy balance, making exaggerated assumptions in order to demonstrate that only $E_{t}^{\text {comp }}$ is really significant.

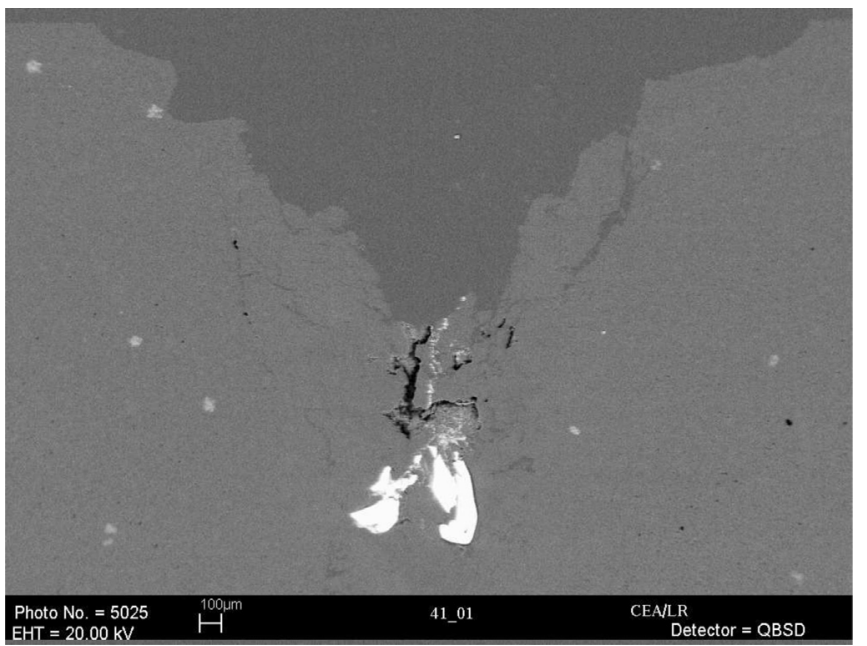

Fig. 5. SEM image of post-mortem cutting of shot \#41. White: remains of the steel projectile. Gray: EDM3 sample. Black (or dark gray): empty spaces. White veins are melted steel from projectile. Small white dots into graphite are metallic inclusions (Vanadium and Titanium) from production cycle. Canyons above projectile remains are due to accidental material pulling out during polishing process.

\subsubsection{Thermal energy in the projectile}

The energy stored in the projectile after impact merely consists of a thermal part which includes shock-release path $E_{p}^{s r}$ and plastic deformation $E_{p}^{\text {plas }}$. An upper value of specific internal energy after the shock-release path is estimated to be $10^{4} \mathrm{~J} \mathrm{~kg}^{-1}$ from the MieGrüneisen equation of state (EOS) of steel. The mass of the projectile being $0.5 \mathrm{mg}$, one finds $E_{p}^{s r}<5 \mathrm{~mJ}$. The other contribution is estimated from plastic deformation $\varepsilon^{p} \sim 1$, average yield stress $Y_{p} \sim 1 \mathrm{GPa}$ and steel sphere volume $V_{p} \sim 6 \cdot 10^{-11} \mathrm{~m}^{3}$ :

$E_{p}^{\text {plas }}=Y_{p} \cdot \varepsilon^{p} \cdot V_{p} \sim 60 \mathrm{~mJ}$

Thus, the thermal energy of the projectile only represents $1.4 \%$ of the input energy. However, it should be noted that, since the energy required to entirely melt the projectile is around $0.6 \mathrm{~J}$ [31], it may have been superficially melted. That is consistent with SEM observations presented in Section 2.

\subsubsection{Kinetic energies}

The maximum fragment velocity $v_{f}$ recorded by video is around $200 \mathrm{~m} \mathrm{~s}^{-1}$. Now suppose that total fragments volume is equal to crater volume $\left(3.6 \mathrm{~mm}^{3}\right.$ ): fragments kinetic energy is $E_{f}^{\text {kin }} \sim 120 \mathrm{~mJ}$. $E_{t}^{k i n}$ can be calculated from momentum conservation and experimental data since the projectile remains inside the target.

$m_{p} \cdot v_{p}=m_{t} \cdot v_{t}+m_{f} \cdot v_{f}$

The target mass was $18.6 \mathrm{~g}$, hence its velocity is $v_{t} \sim 0.18 \mathrm{~m} \mathrm{~s}^{-1}$ and its kinetic energy is $E_{t}^{k i n} \sim 0.3 \mathrm{~mJ}$. Finally, fragments and target kinetic energies are a $2.7 \%$ part of the input energy. As a complement to energy balance analysis, we note that the momentum imparted to ejected fragments is less than $50 \%$ of the original momentum of the impactor. It means that momentum enhancement is less than 1.5 , which is consistent with the results of Walker and Chocron [32] for similar impact velocities and material strength.

\subsubsection{Fragmentation energies}

The fragmentation energy $E^{\text {frag }}$ increases with the new surface creation, i.e. when fragment size decreases. According to Irwin formula, the fracture energy per unit surface $\gamma$ is given by Eq. (8) where $K_{I c}$ is the fracture toughness, $\nu$ the Poisson ratio and $E$ the Young modulus.

$\gamma=K_{I c}^{2} \cdot \frac{\left(1-\nu^{2}\right)}{2 \cdot E}$

The fracture toughness is unknown for EDM3. Nonetheless, many previous studies [33-38] have shown that the fracture toughness of various polycrystalline graphite characterized by 


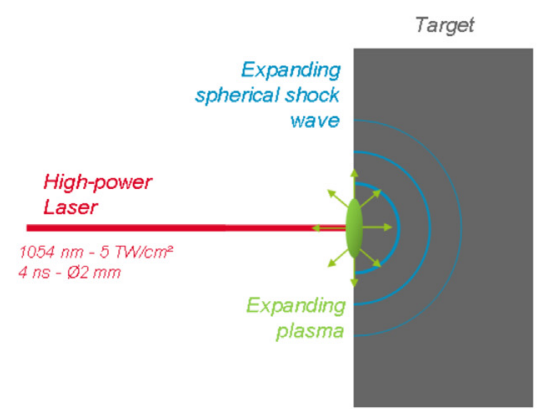

(a) Principle of shock wave created by laser-matter interaction.

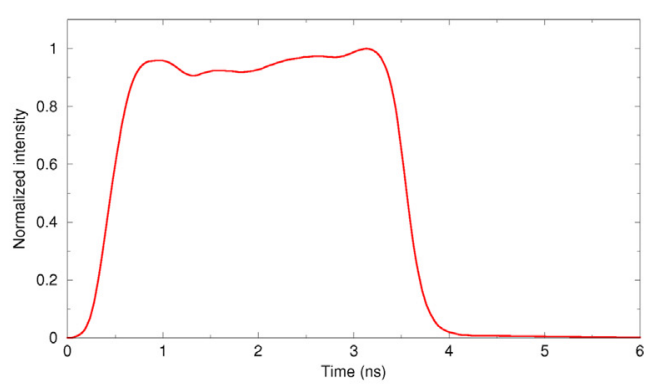

(b) Normalized intensity of the laser beam versus time.

Fig. 6. Characteristics of the $5 \mathrm{TW} \mathrm{cm}^{-2}$ shot at LULI 2000. Spot diameter: $2 \mathrm{~mm}$.

different means is around $1 \mathrm{MPa} \mathrm{m}^{1 / 2}$. Thus, the fracture energy for EDM3 is $\gamma \sim 40 \mathrm{~J} \mathrm{~m}^{-2}$. In the extreme case, we assume that the cratering process is totally governed by fragmentation - and not by compaction of the porous material. To produce the crater volume $V_{\text {crat }}$, the required fragmentation energy is

$E_{t}^{\text {frag }}=\gamma \cdot \frac{V_{\text {crat }} \cdot S_{\text {frag }}}{V_{\text {frag }}}$

where $V_{\text {frag }}$ and $S_{\text {frag }}$ are respectively the volume and the surface of a characteristic fragment size. For spherical fragments of radius $r$ fragmentation energy becomes

$E_{t}^{\text {frag }}=\frac{3 \cdot \gamma}{r} \cdot V_{\text {crat }}$

Fig. 8 presents the evolution of fragmentation energy according to characteristic fragment size $d=2 r$ for a $3.6 \mathrm{~mm}^{3}$ crater volume. Assumption of inter-granular fragmentation gives us the minimum fragment size for EDM3 as its $5 \mu \mathrm{m}$ grain size and fragmentation energy is about $170 \mathrm{~mJ}$. Grady [39] proposed a relation between characteristic fragment size and strain rate based on an equilibrium balance of surface energy and kinetic energy:

$d=\left(\frac{24 \cdot G_{c}}{\rho \cdot \dot{\varepsilon}^{2}}\right)^{1 / 3}$

where $G_{c}=2 \gamma$ is the strain energy release by unit surface. Given strain rate in the order of magnitude of $10^{7} \mathrm{~s}^{-1}$, characteristic fragment size should be above grain size, around $20 \mu \mathrm{m}$. Finally and according to Fig. 8, fragmentation energy might be around $45 \mathrm{~mJ}$ which is $1 \%$ of the input energy. Therefore, projectile kinetic energy is mainly consumed by the target compaction energy which may represent around 95\% of the input energy $E_{p}^{k i n}$.

\subsubsection{Compaction energy}

In order to estimate the energy consumed by compaction in the target we use the confined compression curve of EDM3 presented in Fig. 9. Ignoring elastic phenomena, this energy is given by the plastic compaction part of this curve. It gives an energy $e^{c o m p}=10^{8} \mathrm{~J} \mathrm{~m}^{-3}$ for a total compaction of a unit volume. The impact of a 0.5 -mm-diameter steel sphere on a target at $4200 \mathrm{~m} \mathrm{~s}^{-1}$ creates a very short ( $\sim 100 \mathrm{~ns}$ ) shock wave expanding spherically outwards (cf. 2.2.1). The pressure reaches $40 \mathrm{GPa}$ near the impact point and decreases when the depth increases. Because EDM3 is totally compacted when pressure is beyond $1 \mathrm{GPa}$, one assumes that compaction is complete or does not exist. The consumption of $95 \%$ of $E_{p}^{k i n}=4.5 \mathrm{~J}$ means the original volume to be compacted is:

$V^{\text {comp }}=\frac{2}{3} \cdot \pi \cdot R^{3}=\frac{0.95 \cdot E_{p}^{\text {kin }}}{e^{\text {comp }}}=43 \mathrm{~mm}^{3}$

Thus, there is no more compaction beyond a radius $R=2.7 \mathrm{~mm}$ from the impact point. By volume reduction, the half sphere of radius $R$ becomes a hemispherical shell. Assuming a total compaction of the matter, its internal radius, i.e. the crater radius, is $r=1.7 \mathrm{~mm}$. Hence, the crater volume is around $9.8 \mathrm{~mm}^{3}$. Recalling that the experimental maximum crater diameter, depth and volume are respectively $1.75,1.45 \mathrm{~mm}$ and $3.6 \mathrm{~mm}^{3}$, we have shown that this simple study gives good orders of magnitude. The discrepancy in volume may come from an overestimation of the available energy for compaction $E_{t}^{\text {comp }}$, or from the assumption that the material density after compaction is $2265 \mathrm{~kg} \mathrm{~m}^{-3}$. In fact, if comminution is associated with compaction process, some residual porosity (due to the so-called dilatancy phenomenon) may still be present after unloading.

\subsubsection{Conclusion on energy balance method}

The energy partitioning in our experiment significantly differs from Gault and Heitowit [28] and Braslau [29] where the kinetic

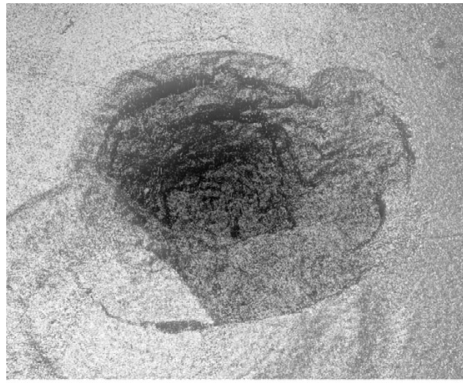

(a) 3D-reconstruction from profilometric data.

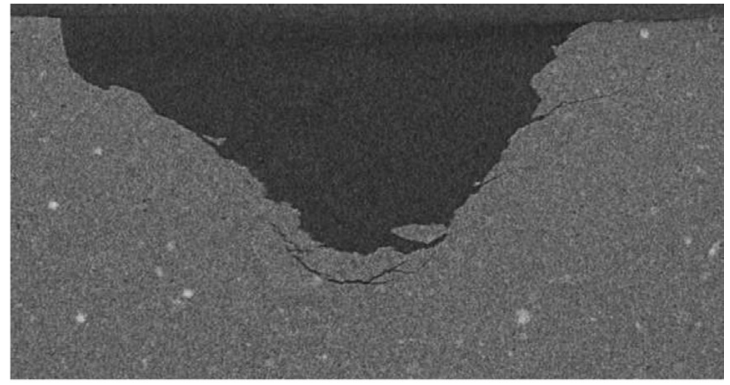

(b) High-resolution $(6.5 \mu \mathrm{m} / p x)$ tomographic slice (front face up).

Fig. 7. Crater from the $5 \mathrm{TW} \mathrm{cm} \mathrm{cm}^{-2}$ shot at LULI 2000 . 
Table 3

Crater characteristic dimensions from the LULI 2000 shot.

\begin{tabular}{lll}
\hline Laser intensity $I_{b}\left(\mathrm{TW} \mathrm{cm} \mathrm{cm}^{-2}\right)$ & 5 & Normalized by the spot diameter \\
Crater volume $($ with spall $) V_{\text {crat }}\left(\mathrm{mm}^{3}\right)$ & 8.5 & \\
Spot diameter $(\mathrm{mm})$ & 2 & \\
Crater depth $p_{c}(\mathrm{~mm})$ & 1.3 & 0.65 \\
Crater diameter $d_{c}(\mathrm{~mm})$ & 2.3 & 1.15 \\
Spall depth $p_{s}(\mathrm{~mm})$ & 0.4 & 0.2 \\
Spall diameter $d_{s}(\mathrm{~mm})$ & 3.4 & 1.7 \\
\hline
\end{tabular}

energy of fragments is greater. The difference is supposed to come from the much stronger excavation in their experiments on basalt and sand. Their measurements of the total ejected mass of debris was respectively 370 and 4000 times the impactor mass, whereas this ratio is only 10 in our case.

To conclude, one can say this first approach gives orders of magnitude of the effects of hypervelocity impacts on EDM3. But it cannot predict the ejected fragments volume because of the difference between the orders of magnitude of the various energy consumption phenomena. It does not take account of surface spalling and neither explains why the projectile remains in the target after impact - even if the latter phenomenon has already been observed by Tanabe et al. [16]. The possible presence of macro-cracks cannot be predicted and damaged areas around crater walls are not described. Moreover, even if the depth is correct, the crater volume is overestimated. Hydrodynamic simulations should be more predictive as regards these considerations.

\section{Modeling}

\subsection{Hydrocodes}

The following models were implemented into Hésione Eulerian hydrocode developed at CEA. It deals with multi-material flows in explicit mode on Cartesian 2D or 3D grid using the BBC numerical scheme [40]. It solves the three conservation equations (mass, momentum and energy) where stress tensor is divided into two parts:

- Pressure: calculated by means of an EOS;

- Deviatoric stress tensor: given by an incremental constitutive relation.

However, Hésione has no laser-matter interaction model. In order to simulate the LULI 2000 shot, we used Esther, a 1D

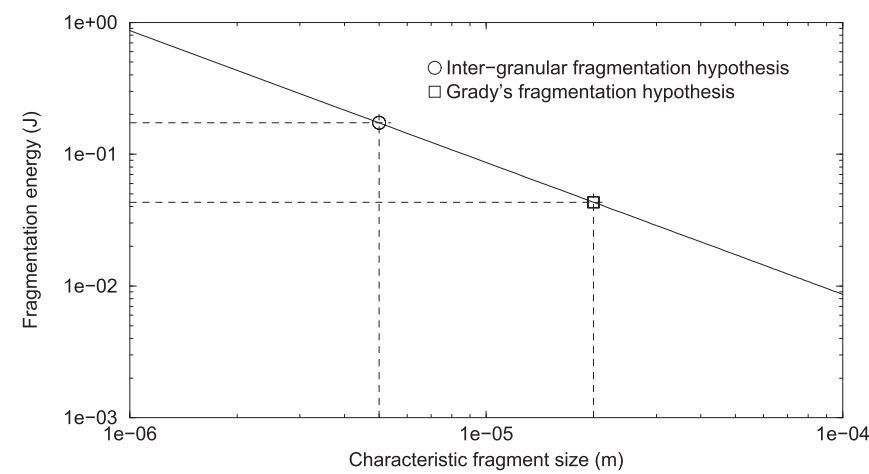

Fig. 8. Fragmentation energy as a function of characteristic fragment size $d=2 r$. Intergranular fragmentation would mean that minimum fragment size for EDM3 is $5 \mu \mathrm{m}$ and thus, maximum fragmentation energy would be about $170 \mathrm{~mJ}$. But, according to Grady [39], the characteristic fragment size should be around $20 \mu \mathrm{m}$ and the fragmentation energy equal to $\sim 45 \mathrm{~mJ}$. See text for more details.

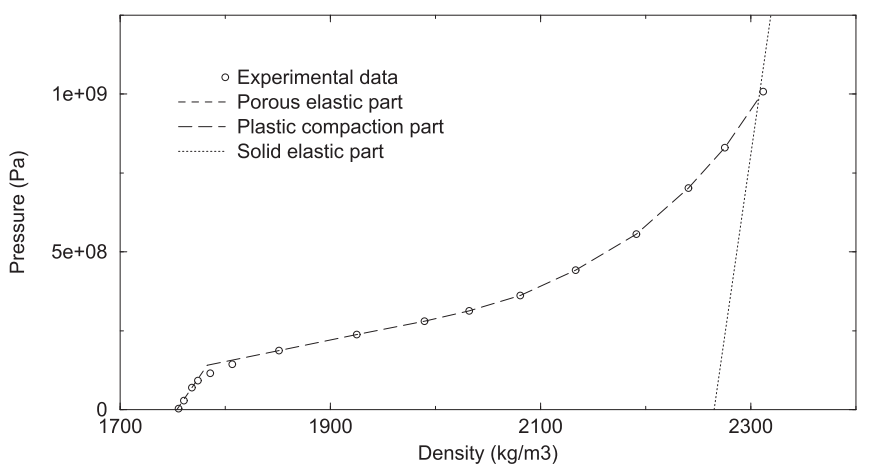

Fig. 9. Confined compression curve of porous graphite EDM3 modeled in two parts The solid elastic part is given indicatively. The compaction energy is approximated by the area under the compaction curve: $e_{\text {comp }}=10^{8} \mathrm{~J} \mathrm{~m}^{-3}$.

Lagrangian hydrodynamic code developed at CEA. It numerically solves laser wave propagation into plasma along with thermal diffusion and hydrodynamic processes. It enabled us to extract equivalent dynamic loading, i.e. temporal pressure law, induced by the expanding plasma on the sample surface. This pressure law becomes an input parameter of Hésione simulation. Until the end of the pressure deposit (a few ns), computation is done in Lagrangian mode and then, completed in Eulerian mode.

\subsection{Models for EDM3 sample and steel sphere}

The steel projectile is described with a classical model for 304 stainless steel: a Mie-Grüneisen EOS associated with an elasticperfectly-plastic constitutive relation. A failure model is included, with thresholds for both principal stress (tensile) and plastic deformation.

\subsubsection{Porous model}

The behavior of EDM3 is described with the POREQST model, which supplies EOS and constitutive relations for porous materials and it is implemented into Hésione Eulerian hydrocode presented in Section 4.1. A complete description of this model is done by Tokheim et al. [41] and some of its features are shown in Fig. 10. Standard mechanical properties of EDM3 such as elastic moduli are used as input parameters. A static compression curve measured in confined compression tests ( $c f$. Fig. 9), i.e. under uniaxial strain, is used to display compaction. Densified graphite is described with a Mie-Grüneisen EOS, whose parameters have been fitted to the 7832 SESAME table. This model also includes a pore re-opening curve defined through its intersection with the dense EOS via the parameter $P l$ ( $c f$. Fig. 10). Tension never goes beyond this value but decreases because of pores opening.

The damaging process representation needs to define criteria and treatments. In case of a hypervelocity impact of a small steel sphere onto a target, the main damage is due to tensile and shear strength. Senft and Stewart [8] compared results from simulations with both tensile and shear damage as well as with tensile damage only. It showed tensile loading is mainly responsible for the damaging process. Indeed, tensile damage is due to hoop stress arising from the material radial motion in a spherical geometry whereas shear damage is responsible for the comminuted zone near the impact point. Thus, we restricted our simulations to a tensile criterion. When the matter in an Eulerian cell has a negative pressure located on the pore re-opening curve of the POREQST model and if its intermediary porosity $\alpha_{i}=\rho_{s 0} / \rho_{0 i}$ is higher than a critical value, then a cavitation algorithm relaxes pressure and stress to zero, and sets a damage variable (Indendo in Hésione) to 1. 


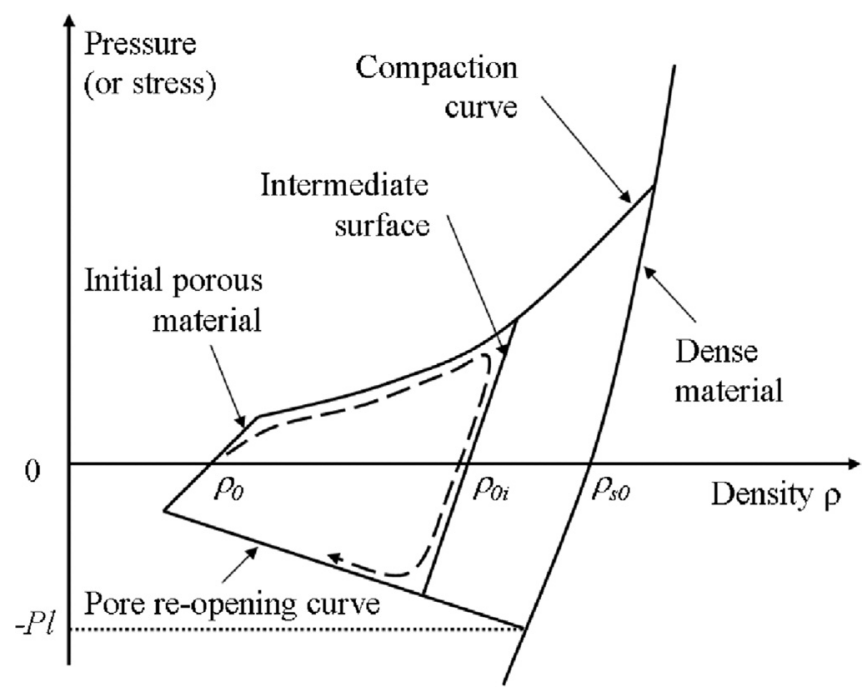

Fig. 10. Schematic of the POREQST model in zero internal energy plane. A typical loading-unloading path is given by the dashed arrow: first, the behavior of initial porous material is described by an elastic surface; then, compaction occurs until the unloading; pressure comes back to 0 following an intermediate elastic surface; next, if material is put under tension, it follows the same intermediate surface down to the irreversible pore re-opening phenomenon.

This variable continuously feeds back on $P l$ in each cell, setting it to 0 if equal to 1 . In our case, the porosity threshold for the onset of cavitation is $\alpha_{i}^{\text {th }}=1.2$.

\subsubsection{Brittle failure model}

The brittle failure is included in our model via a strain rate dependence of the parameter $P l$. Recalling that strain rates $\dot{\varepsilon}$ can exceed $10^{7} \mathrm{~s}^{-1}$ in HVI, we follow the work of Grady and Kipp [42], Denoual [43], Forquin and Hild [44] and Melosh et al. [45] and use a formulation deduced from the Weibull theory of the weakest flaw:

$P l=K(m+3)(m+4)^{-(m+4) /(m+3)} \beta^{-1 /(m+3)} \dot{\varepsilon}^{3 /(m+3)}$

with $K$ the longitudinal modulus and $\beta$ defined as follows

$\beta=\frac{8 \pi C_{g}^{3} k}{(m+1)(m+2)(m+3)}$

In this expression, $C_{g}$ is the maximum constant fracture growth velocity, classically estimated as $40 \%$ of material sound speed or $70 \%$ of Rayleigh wave velocity [46], $C_{g}=900 \mathrm{~m} \mathrm{~s}^{-1}$. The so-called Weibull parameters $k$ and $m$ are defined by Grady and Kipp [42] as

$n=k \varepsilon^{m}$

where $n$ is the number of flaws per unit volume activated at or below a tensile strain $\varepsilon$. Note that $k$ may vary of many orders of magnitude depending on material specificity.

Following Denoual [43] and Forquin and Hild [44], we also introduced in our model a static-to-dynamic strain rate transition $\dot{\varepsilon}_{s / d}$ above which Eq. (13) applies. Below $\dot{\varepsilon}_{s / d}$, a constant value $P l_{0}=70 \mathrm{MPa}$ is assumed for $\mathrm{Pl}$ (according to Table 1). For consistency, the unknown parameters $k, n$ and $\dot{\varepsilon}_{s / d}$ must obey the following relation:

$P l\left(\dot{\varepsilon}_{s / d}\right)=P l_{0}$

\section{Numerical results and discussions}

\subsection{MICA shots}

This section presents 2D-axisymmetric numerical simulations of MICA shots performed with the Hésione Eulerian component and models described in the previous section. We examine the sensitivity of numerical results to cell size and unknown parameters $k, m$ and $\dot{\varepsilon}_{s / d}$.

\subsubsection{Parameter fitting procedure}

In a first simulation, we used a Weibull modulus $m=9$ taken from another graphite in literature [47]. The quasi-static-todynamic strain rate transition has been arbitrarily fixed to $\dot{\varepsilon}_{s / d}=10^{-2} \mathrm{~s}^{-1}$. This choice with Eq. (16) leads to $k=9.39 \times 10^{10} \mathrm{~m}^{-3}$. The result is shown on the upper half of Fig. 11 . As we can see, the damage area is too small and the crater borders are left undamaged. This behavior may be explained by introducing five Lagrangian probes in simulation (their names and positions appear on Fig. 11) and following their path in the stress-strain rate plane ( $c f$. Fig. 12). It appears clearly that they all lie below the dynamic tensile strength $\mathrm{Pl}$. Thus, our procedure to build new sets of Weibull parameters will be to ensure that some of them (P1, P6, $\mathrm{P} 25, \mathrm{P} 28$ ) are subject to damage, whereas P16 is not. It is clear from Fig. 12 that there are many sets of Weibull parameters satisfying this requirement. Among them, two are plotted on Fig. 12 and will be studied in the following of this paper: $W 1=\{m=35$, $\left.k=4.3 \times 10^{67} \mathrm{~m}^{-3}, \dot{\varepsilon}_{s / d}=10^{-2} \mathrm{~s}^{-1}\right\}, \mathrm{W} 2=\left\{m=14, k=10^{34} \mathrm{~m}^{-3}\right.$, $\left.\dot{\varepsilon}_{\mathrm{s} / d}=10^{2} \mathrm{~s}^{-1}\right\}$.

\subsubsection{Results and discussion}

The bottom part of Fig. 11 shows simulation results with set W1. Fig. 13 is a comparison between simulation and experiment.

First we note that radial cracks predicted by simulation are not observed on tomography and SEM images. This discrepancy can come from an inaccurate modeling or healing may have occurred [48]. Moreover, the projectile penetration depth is underestimated. This might be related to uncertainties in the steel sphere model,

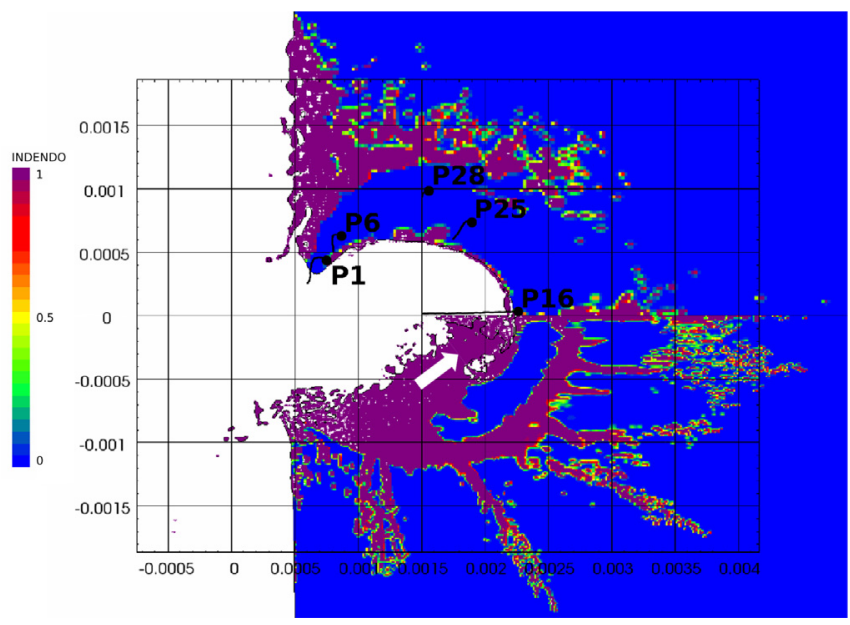

Fig. 11. Impact velocity at $4100 \mathrm{~m} \mathrm{~s}^{-1}$ (front face on the left). Damages in EDM3 at $\sim 5 \mu \mathrm{s}$ after impact (projectile came from left). Indendo $=1$ means totally damaged material. Indendo $=0$ means no damage. Top: Weibull parameters $m=9$ and $k=9.39 \times 10^{10} \mathrm{~m}^{-3}$. Black dots and line are respectively final positions and trajectories of probes versus time. Bottom: Weibull parameters $\mathrm{W} 1 \quad(m=35$ and $k=4.3 \times 10^{67} \mathrm{~m}^{-3}$ ). Grid unit is meter. Correctly adapted Weibull parameters improve the crater shape and the damaged area. Moreover, the trapping of the projectile is reproduced. 


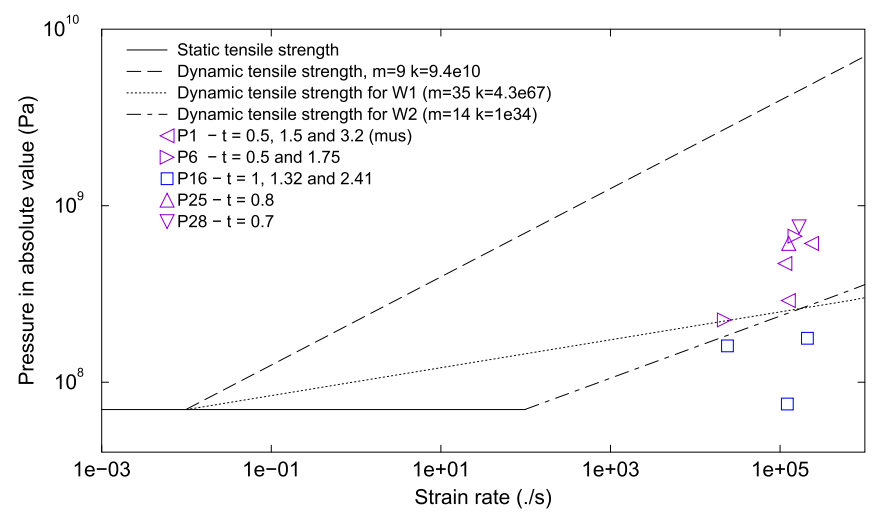

Fig. 12. Numerical fitting of the two Weibull parameters $k$ and $m$. Violet triangles give pressures and strain rates at different times for Lagrangian probes where damaging is wanted. Blue squares are from the probe where damaging is not wanted. The fitting consists in the choice of the combined Weibull parameters ( $k$ and $m$ ) and static-todynamic strain rate transition $\left(\dot{\varepsilon}_{S / d}\right)$ keeping blue squares under dynamic tensile strength and violet triangles above. Without experimental values of $k, m$ and $\dot{\varepsilon}_{s / d}$, there are many admissible combinations. Two of them are presented here. (For interpretation of the references to color in this figure legend, the reader is referred to the web version of this article.)

especially its yield strength. We also observe an undamaged zone under the crater bottom which corresponds to densification. It is expected that taking shear/compression damaging into account would affect this aspect. Despite these disagreements, the simulation reproduces the major experiment features:

- Fig. 13 shows that surface spall diameter is $\sim 3 \mathrm{~mm}$;

- The velocity of ejected fragments mainly goes from 20 to $180 \mathrm{~m} \mathrm{~s}^{-1}$;

- The steel sphere is trapped by a damaged material flow which comes after crater creation (see white arrow in Figs. 11 and 13). These debris are probably aggregated to partially melted metal, leading to a crater depth of $\sim 1.2 \mathrm{~mm}$;

- In addition of the crater depth and diameter, we note that the last simulation also reproduces the crater shape. However,

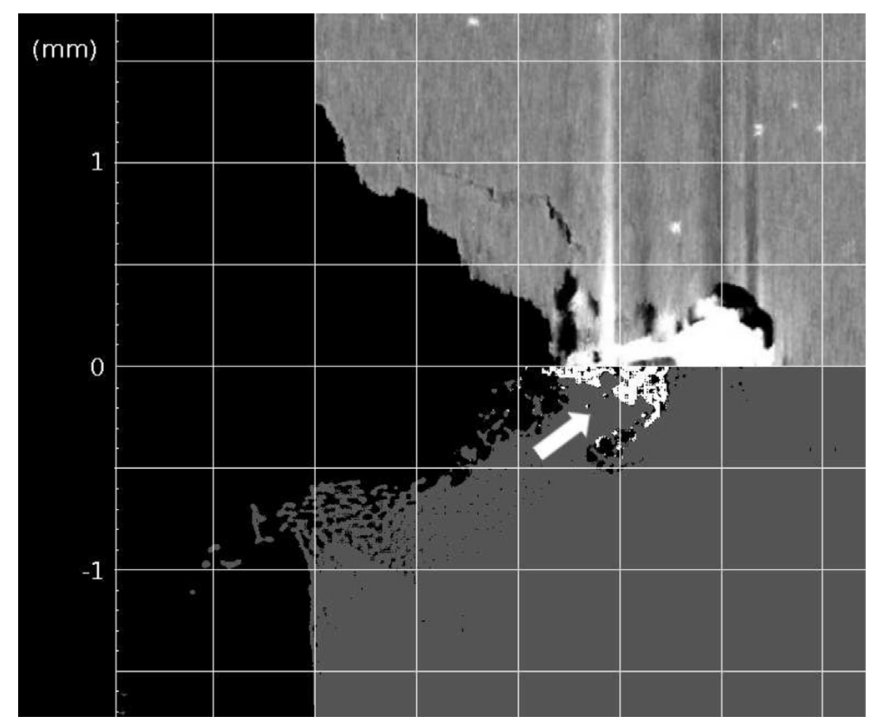

Fig. 13. Comparison between experimental and numerical results. Top: tomography of shot \#38. Bottom: simulation $(\mathrm{t} \sim 5 \mu \mathrm{s}$ ) from the bottom part of Fig. 11. White: projectile. Gray: graphite. Black: empty spaces. Projectile came from left. The trapping phenomenon is correctly reproduced even if the projectile penetration depth is underestimated. Apparent damaged areas are similar.

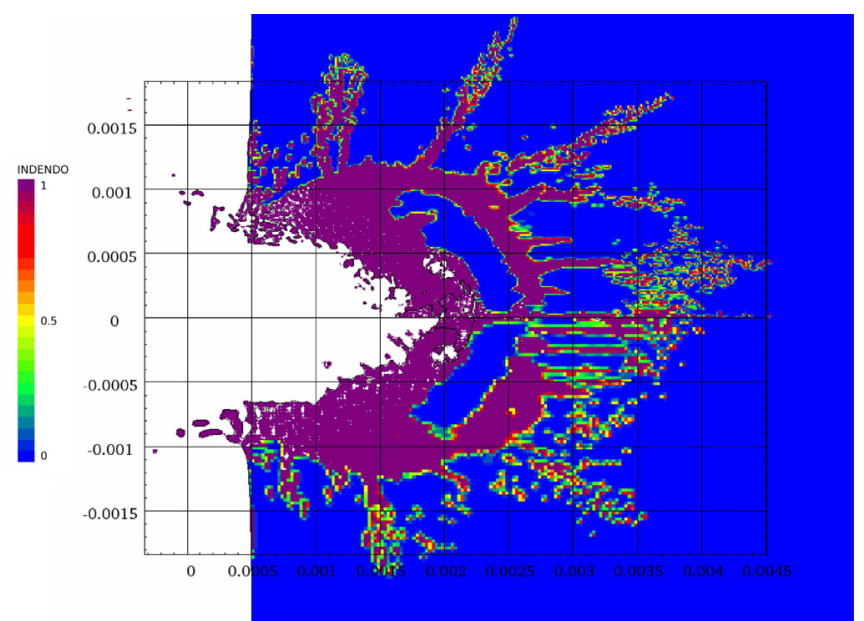

Fig. 14. Impact velocity at $4100 \mathrm{~m} \mathrm{~s}^{-1}$ (projectile came from left). Damages in EDM3 at $\sim 5 \mu$ s after impact. Weibull parameters W1 $\left(m=35\right.$ and $\left.k=4.3 \times 10^{67} \mathrm{~m}^{-3}\right)$. Top: cell size is $12.5 \times 12.5 \mu \mathrm{m}$. Bottom: $25 \times 25 \mu \mathrm{m}$.

remembering that fragments still move at the end of the simulation, this point should be addressed with caution.

In the damaged area, the cell size used for computations was $12.5 \times 12.5 \mu \mathrm{m}$. It ensures both a good convergence level and a reasonable computation time - two and a half hour on an eightcore computer. The mesh convergence of this simulation is illustrated on Fig. 14, where no major difference can be seen with a simulation on a $25 \times 25 \mu \mathrm{m}$ grid. At most, mesh refinement slightly influences surface spalling and radial cracks length.

Finally, the sensitivity of our numerical results to the choice of Weibull parameters has been investigated. A comparison is made between simulations using sets W1 and W2 on Fig. 15. There is no much discrepancy on size, aspect or phenomenology. But, we notice a slight increase of surface spall and cracks length, which is consistent with the fact that W2 predicts lower tensile strength at intermediate stress rates (see Fig. 12).

To conclude, the selected cell size seems to be adapted. Without experimental values of the Weibull parameters, a numerical fitting is useful and gives good results whatever the choice of the quasistatic-to-dynamic transition strain rate. To test the validity of

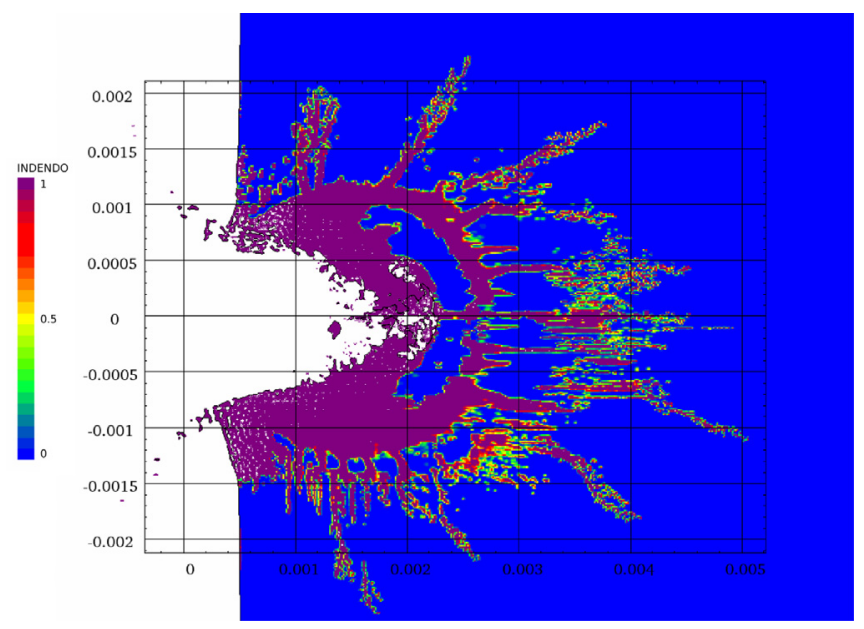

Fig. 15. Impact velocity at $4100 \mathrm{~m} \mathrm{~s}^{-1}$ (projectile came from left). Damages in EDM3 at $\sim 5 \mu$ s after impact. Cell size $12.5 \times 12.5 \mu \mathrm{m}$. Top: Weibull parameters $\mathrm{W} 1(\mathrm{~m}=35$ and $\left.k=4.3 \times 10^{67} \mathrm{~m}^{-3}\right)$. Bottom: Weibull parameters W2 $\left(m=14\right.$ and $\left.k=10^{34} \mathrm{~m}^{-3}\right)$. 
these choices with a different loading, we simulated the laserinduced shock of the LULI 2000 shot.

\subsection{LULI 2000 shot}

From experimental intensity, Esther simulation provides pressure loading on sample surface (see Fig. 16a). This pressure is used as an input of the Hésione simulation. The spatial distribution of the pressure onto the target is idealized as a $2-\mathrm{mm}$-diameter rounded crenel. Cells are now $1 \times 1 \mu \mathrm{m}$, which is necessary because of the

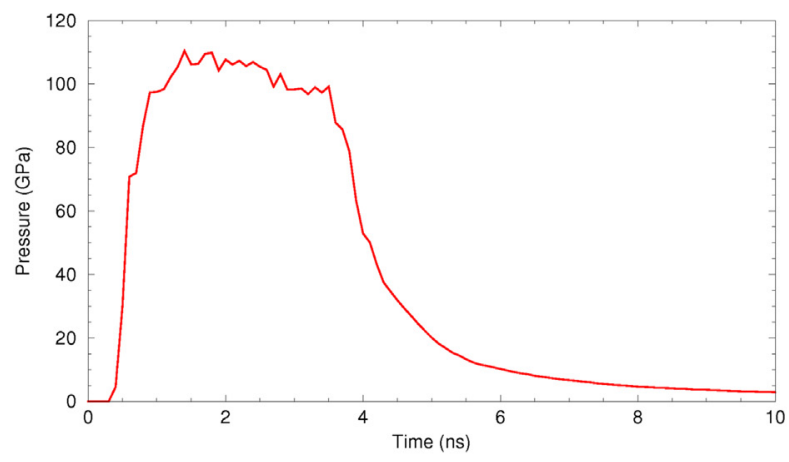

(a) Esther simulation giving the pressure law applied on the EDM3 target surface.

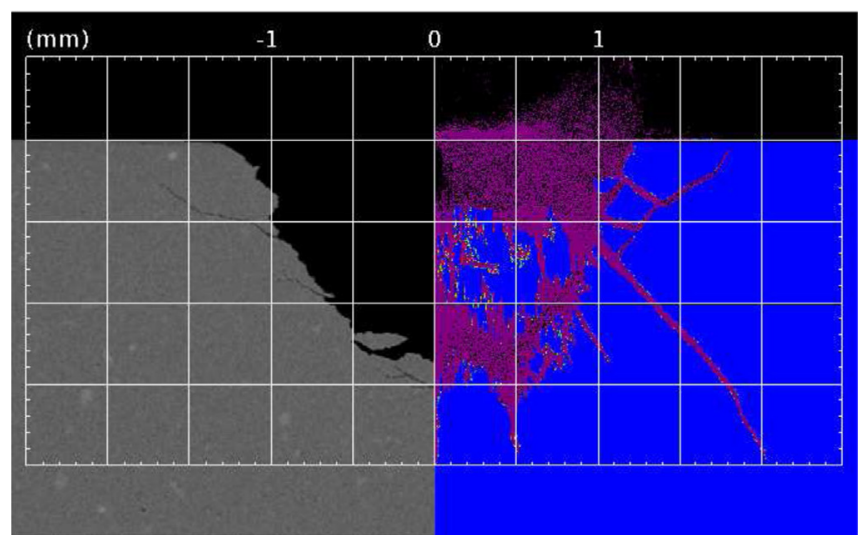

(b) Comparison between Hésione simulation (Weibull parameters W1) and experimental tomography from Fig. 7.

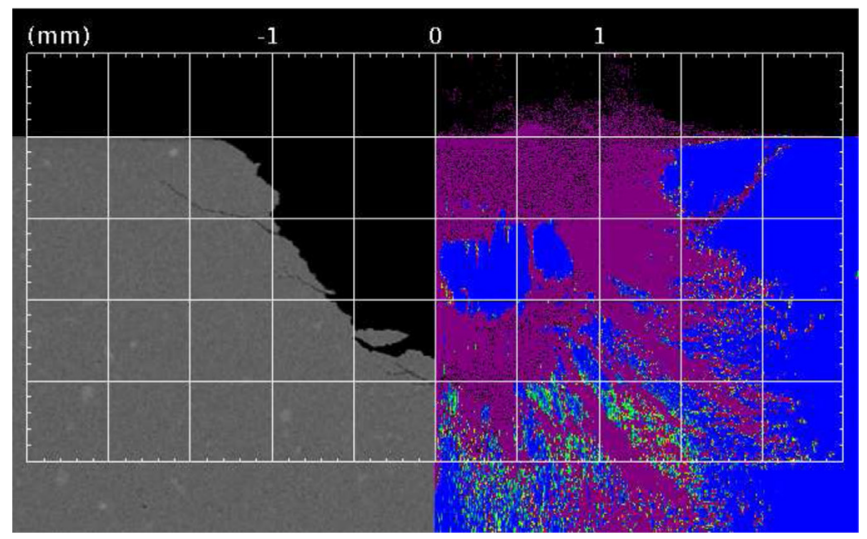

(c) Comparison between Hésione simulation (Weibull parameters W2) and experimental tomography from Fig. 7.

Fig. 16. Simulation of the LULI 2000 shot at $5 \mathrm{TW} \mathrm{cm}^{-2}-4 \mathrm{~ns}-2 \mathrm{~mm}$ spot size. b) and c) present crater's characteristics with set $\mathrm{W} 1$ and $\mathrm{W} 2$ respectively. On the right are the damage contours where violet means the material is totally damaged and blue means no damage at all. (For interpretation of the references to color in this figure legend, the reader is referred to the web version of this article.) short duration of the laser impulse. It must be noticed that it widely increases the computation time (a day on 512 cores). Simulations have been made for both sets of Weibull parameters W1 and W2. Comparisons with experimental results are presented in Fig. 16b and c respectively. Contrary to HVI configuration, laser simulations are strongly affected by the choice of the Weibull parameters and clearly show the superiority of set $\mathrm{W} 1$ :

- The vertical expanse of the damaged zone for W1 is in good agreement with the observed crater depth, whereas the simulation with W2 strongly overestimates it;

- For W1, the radius of the outermost crack is consistent with the experimental spall diameter and is much alike the subsurface crack discussed in 2.2.2;

- The radius of the highly damaged zone for $\mathrm{W} 1$ is $\sim 1.2 \mathrm{~mm}$, which is close to the experimental value, whereas the simulation with $\mathrm{W} 2(\sim 1.5 \mathrm{~mm})$ overvalues it.

As expected, maximum strain rates obtained in the simulation $\left(\sim 10^{6} \mathrm{~s}^{-1}\right)$ are larger than in HVI. However, we noted that the damaged area is larger with W2 than with W1. It suggests that the damage occurred at strain rates where $\mathrm{W} 1$ yields greater tensile strength than $\mathrm{W} 2$, i.e. where corresponding strain rates are lower than $10^{4} \mathrm{~s}^{-1}$ ( $c f$. Fig. 12). Indeed, due to its brevity, the laser shock strongly attenuates, and generates a wider range of strain rates than HVI. Finally, the set of Weibull parameters W1 seems to be the best one, and this result reveals the complementarity of laser and HVI experiments for an accurate fitting.

\section{Conclusion}

In this paper, various experiments have been reported on EDM3, a commercial grade of porous, macroscopically isotropic polycrystalline graphite. In the case of HVI tests, performed above $4000 \mathrm{~m} \mathrm{~s}^{-1}$ with a $500 \mu \mathrm{m}$ diameter steel sphere, post-mortem tomographies and SEM observations on recovered samples provide precise crater description and show that projectile is buried below the apparent crater surface. An experiment with high-power laser is also presented, leading to a similar crater but with significantly different loading conditions, such as pressure and strain rate. A detailed energy balance analysis of HVI experiments is proposed. It gives correct orders of magnitude for crater size and provides insight into dominant physical processes. Then, a physically based model is presented which takes brittleness and porosity into account. 2D-axisymmetric hydrodynamic simulations are performed and discussed, suggesting that at least two appropriate sets of Weibull parameters can lead to good agreement with HVI results, especially projectile inclusion below fragmented debris of graphite. Finally, it is shown that simulations of laser experiment may discriminate in favor of one set of parameters, confirming the complementarity of laser and HVI experiments.

\section{Acknowledgments}

The authors would like to express their gratitude to Claude Bianchi for reviewing the English of this paper.

\section{References}

[1] Cour-Palais BG. A career in applied physics: Apollo through space station. International Journal of Impact Engineering 1999;23:153-6.

[2] Davison D, Cour-Palais B, Quan X, Holmquist TJ, Cohen LM, Ramsey R, et al. Computer models of micrometeoroid impact on fused silica glass mirrors. International Journal of Impact Engineering 2003;29:203-14. 
[3] Michel Y, Chevalier JM, Durin C, Espinosa C, Malaise F, Barrau JJ. Hypervelocity impacts on thin brittle targets: experimental data and sph simulations. International Journal of Impact Enegineering 2006;33:441-51.

[4] Tobin M, Andrew J, Haupt D, Mann K, Poco J, Satcher J, et al. Using silica aerogel to characterize hypervelocity shrapnel produced in high power laser experiments. International Journal of Impact Engineering 2003;29:713-21.

[5] Lescoute E, Hallo L, Hébert D, Chimier B, Etchessahar B, Tikhonchuk VT, et al. Experimental observations and modeling of nanoparticle formation in laserproduced expanding plasma. Physics of Plasma 2008;15:1-11.

[6] Herrmann W, Jones AH. Correlation of hypervelocity impact data. In: Fifth symposium on hypervelocity impact. Denver: National Aeronautics and Space Administration; 1973. p. 389-438.

[7] Pierazzo E, Artemieva N, Asphaug E, Baldwin EC, Cazamias J, Coker R, et al. Validation of numerical codes for impact and explosion cratering: impacts on strengthless and metal targets. Meteoritics and Planetary Science 2008;43: 1917-38.

[8] Senft LE, Stewart ST. Modeling impact cratering in layered surface. Journal of Geophysical Research 2007;112:1-118.

[9] Burt RR, Christiansen EL. Hypervelocity impact testing of transparent spacecraft materials. International Journal of Impact Engineering 2003;29:153-66.

[10] Grady DE. The spall strength of condensed matter. Journal of the Mechanics and Physics of Solids 1988;36:353-84.

[11] Numata D, Ohtani K, Anyoji M, Takayama K, Togami K, Sun M. Hvi tests on cfrp laminates at low temperature. International Journal of Impact Engineering 2008;35:1695-701.

[12] Tennyson RC, Lamontagne C. Hypervelocity impact damage to composites. Composites: Part A 2000;31:785-94.

[13] Latunde-Dada S, Cheesman C, Day D, Harrison W, Price S. Hypervelocity impacts into graphite. In: Condensed matter and materials physics conference, vol. 286; 2011. p. $1-10$

[14] www.poco.com. 2012

[15] www.luli.polytechnique.fr/accueil/les-installations/luli2000. 2012.

[16] Tanabe Y, Saitoh T, Akatsu T, Sawaoka A. Crater formation of carbon materials by impact of a high velocity sphere. Carbon 1995;11:1547-52.

[17] Pirri AN. Theory for laser simulation of hypervelocity impact. The Physics of Fluids 1977;20:221-8.

[18] Marsh SP. LASL shock hugoniot dataIn Los Alamos Scientific Laboratory series on dynamic material properties, vol. 5. University of California Press; 1980.

[19] Dautray R, Watteau JP, editors. La Fusion Thermonucléaire Inertielle par laser. Hydrodynamique et Implosion, vol. 2; chap. Eyrolles; 1993. p. 117-8.

[20] Grün J, Decoste R, Rippin BH. Characteristics of ablation plasma from planar, laser-driven targets. Applied Physics Letters 1981;39.

[21] Nebolsine PE. Laser simulation of hypervelocity impact. In: AIAA 14th aerospace sciences meeting. Washington DC: Defense Technical Information Center; 1977 p. AIAA paper N 76-52.

[22] Tokheim RE, Curran DR, Seaman L. Damage hardening assessments for national ignition facility target chamber design. Tech. Rep. UCRL-CR-128686. Lawrence Livermore National Laboratory; 1998.

[23] Shanbing Y, Gengchen S, Qingming T. Experimental laws of cratering for hypervelocity impacts of spherical projectiles into thick target. International Journal of Impact Engineering 1994;1:67-77.

[24] Evans AG, Gulden ME, Rosenblatt M. Impact damage in brittle materials in the elastic-plastic response regime. In: Proceedings of the royal society, vol. A361. London: The Royal Society; 1978. p. 343-65.

[25] Wiederhorn SM, Lawn BR. Strength degradation of glass resulting from impact with spheres. Journal of the American Ceramic Society 1977;60(9-10).
[26] Wiederhorn SM, Lawn BR. Strength degradation of glass impacted with sharp particles: I-ii. Journal of the American Ceramic Society 1979;62(1-2).

[27] Tanabe Y, Saitoh T, Wada O, Tamura H, Sawaoka A. An overview of impact damages in ceramic materials for impact velocities below $2 \mathrm{~km} / \mathrm{s}$. Tech. Rep. 19. Research Laboratory of Engineering Materials, Tokyo Institute of Technology; 1994.

[28] Gault DE, Heitowit ED. The partition of energy for hypervelocity impact craters formed in rock. In: Proceedings of the sixth HVIS, Cleveland, Ohio, vol. 2 1963. p. 419-56.

[29] Braslau D. Partitioning of energy in hypervelocity impact against loose sand targets. Journal of Geophysical Research 1970;75(20):3987-99.

[30] Zel'dovich, Raizer. Physics of shock waves and high temperature hydrodynamic phenomena, vol. 2. Academic Press; 1967.

[31] Chase MW. NIST-JANAF thermochemical tables, vol. 2. American Chemica Society; 1998.

[32] Walker JD, Chocron S. Momentum enhancement in hypervelocity impact. International Journal of Impact Engineering 2011;38:A1-7.

[33] Takahashi S, Aoki S, Miyahara N, Tanaka K, Oku T. Impact fracture toughness of a nuclear graphite measured by the one-point-bending method. Carbon 1993;31:315-23.

[34] Burchell TD. A microstructurally based fracture model for polygranular graphites. Carbon 1996;34(3):297-316.

[35] Salazar A, Padtor JY, Llorca J. In situ observation of damage nucleation in graphite and carbon/carbon composites. Carbon 2002;40:609-16.

[36] Latella BA, Liu T. The initiation and propagation of thermal shock cracks in graphite. Carbon 2006;44:3043-8.

[37] Mirhabibi AR, Rand B. Graphite flake-carbon composites. ii: fracture behavior toughness, notch intensitivity and Weibull modulus. Carbon 2007;45:991-7.

[38] Ayatollahi MR, Berto F, Lazzarin P. Mixed mode brittle fracture of sharp and blunt v-notches in polycrystalline graphite. Carbon 2011;49:2465-74.

[39] Grady DE. Local inertial effects in dynamic fragmentation. Journal of Applied Physics 1982;53:322-5.

[40] Woodward PR, Collela P. The numerical simulation of two-dimensional fluid flow with strong shocks. Journal of Computational Physics 1984;54: 115-73.

[41] Tokheim RE, Curran DR, Seaman L. Computational representation of constitutive relations for porous material. Tech. Rep. DNA-3412F. Lawrence Livermore National Laboratory; 1973.

[42] Grady DE, Kipp ME. Continuum modelling of explosive fracture in oil shale. International Journal of Rock Mechanics and Mining Sciences \& Geomechanics Abstracts 1980;17:147-57.

[43] Denoual C. Approche probabiliste du comportement à l'impact du carbure de silicium: application aux blindages moyens. Ph.D. thesis. Cachan: École Normale Supérieure de Cachan; 1998.

[44] Forquin P, Hild F. A probabilistic damage model of the dynamic fragmentation process in brittle materials. Advances in Applied Mechanics 2010;44:1-72.

[45] Melosh HJ, Ryan EV, Asphaug E. Dynamic fragmentation in impacts: hydrocode simulation of laboratory impacts. Journal of Geophysical Research 1992;97:14735-59

[46] Broberg KB. Constant velocity crack propagation - dependence on remote land. International Journal of Solids and Structures 2002;39:6403-10.

[47] Erck RA, Maiya PS. Fracture behavior of graphite coated with titanium compounds by chemical vapor deposition. Materials Science and Engineering 1998;A251:251-4.

[48] Hirth JP, Hucke EE, Coble RL. Flow equations for graphite. Carbon 1976;14: 19-22. 